\title{
Road Impregnating Materials, as an Effective Tool for the Protection and Restoration of Asphalt Pavement
}

\author{
Marina Vysotskaya ${ }^{1}$, Eugenia Vlasova $^{1}$, Svetlana Shekhovtsova ${ }^{2 *}$, and Victoria Vasilyeva ${ }^{3}$ \\ ${ }^{1}$ Belgorod State Technological University named after V.G. Shukhov, 46 Kostyukova str., Belgorod, \\ 308012, Russia \\ ${ }^{2}$ National Research Moscow State University of Civil Engineering, 26 Yaroslavskoye Shosse, \\ Moscow, 129337, Russia \\ ${ }^{3}$ Orel State University, 95 Komsomolskaya str., Orel, 302026, Russia
}

\begin{abstract}
The paper considers the problem of increasing the service life of road asphalt concrete coatings in conditions of year-round operation by road impregnating materials protection from the effects of climatic and operational factors. Objects of research are various domestic road impregnating materials. The subject of research is estimation methodology of road impregnating materials efficiency, modeling effects of the exposed asphalt during operation in the Central Federal District. The article proposes method of estimation of the impregnating materials resistance to different operational factors and consistent scheme of their impact on the object under study is proposed. We conducted comprehensive assessment of road impregnating materials and the effect of their influence on indicators of quality of asphalt concrete and proposed the mechanism of action to protect road impregnating materials.
\end{abstract}

\section{Introduction}

Traffic safety largely depends on the quality of the road surface. Providing year-round defect-free operation of the automobile road is possible by the implementation of the coating protection from the effects of climatic and operational factors or the decrease of their role in the aging of the coating.

Currently the protection technology of asphalt concrete with latex impregnation is widespread, but no mention of the use of anhydrous impregnating compositions to protect asphalt concrete exists.

This work considers the waterless road impregnating materials (RIM) [1] which are the effective technology solution allowing to protect road asphalt concrete coverings from negative impacts of natural and technogenic character that provides decrease in resource intensity of their operation. Their main objective is to fill time and microcracks of a covering, to give it hydrophobic properties, and, according to a number of producers, to rejuvenate bitumen as a part of an asphalt concrete covering.

* Corresponding author: SHehovtsovaSYU@mgsu.ru 
According to the developed concept of road economy development in Russia till 2030 and the passport of the "Safe and Qualitative Roads" project approved by council under the President of the Russian Federation for strategic development and priority projects by 2025 $85 \%$ of a road network of 37 largest agglomerations have to be brought to a standard state, by 2030 the formation of a framework of speedways have to be completed [2]. And it means, the road-building branch should make a lot for achievement of objectives.

In such conditions, the main objective of branch - using preventive technologies to keep the existing road network of the country in the trouble-free working condition. And it is necessary to make it quickly, cheap, technologically simply and surely effectively.

Time is ruthless to highways. Under the influence of set of aggressive factors of the external environment and dynamically increasing transport loading, system weakening and violation of structural communications in an asphalt concrete framework at a stage of commissioning of the object is observed. Such destructive processes are initiated under the influence of oxidizing reactions in bitumen as a result of which brittle properties increase and adhesive indicators of organic knitting decrease. Visually these processes are shown in the form of peeling, chipping with loss of thickness of a coat layer, formation of cracks that consistently leads to emergence of critical defects of asphalt pavements of highways [3].

Today an effective preventive method of preservation of a covering and extension of service life is processing of his surface with the road impregnating materials (RIM). A main objective of use of such compositions is the formation of a strong, dense protective layer steady against influence of moisture and attrition from wheels of motor transport which is characterized by high adhesion to an asphalt concrete covering and penetrating ability [413]. The relevance of their application in road-building branch became the driver for the market of the RIM in Russia. The analysis of production of this segment has shown that its range is widely presented by the imported compositions as well as their domestic analogs. The normative document regulating their quality is ODM [1].

\section{Theory}

According to theoretical premises $[14,15,16,17,18,19]$, the use of the RIM on highways has to prolong life cycle of asphalt pavement with the minimum amount of defects. The operation principle of the RIM in this case is that after drawing on a surface, it gets deep into coverings, forming on it a thin film. The use of the rejuvenating and combined impregnating structures leads to change of properties of organic binders, thereby, improves properties of asphalt concrete in a top layer of a covering [1]. In a general view the effect of use of impregnating materials (figures 1,2), has to be in weakening of impact on a covering of adverse climatic factors, increase in corrosion resistance, increase in resistance to abrasion and improvement of low-temperature properties of asphalt concrete.

However in practice we know the cases of peeling of a covering surface after drawing impregnations, easing and crumbling of gravel grains out of the top asphalt concrete layer, etc. What is the reason of it?

In this case the classical principle of double standards is observed. Serious requirements are imposed to the binding substance for asphalt concrete: high heat resistance and temperature of fragility, compatibility with stone material, the minimum aging, a significant amount of various viscosity of organic binders, corresponding to the requirements, and imitating its behavior in various working conditions. But, when there is a question of the impregnating materials performing function of the protective layer perceiving all weight of operational and climatic factors it is enough to define such indicators as: conditional viscosity, uniformity, adhesion for the RIM and change of water saturation and durability at $50^{\circ} \mathrm{C}$ of core samples taken from a covering before drawing the RIM. 

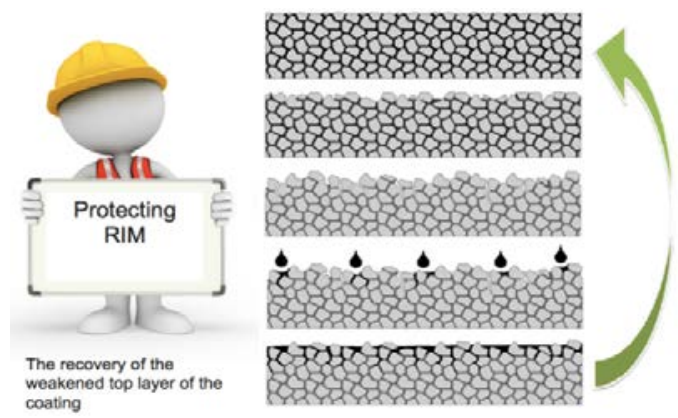

Fig. 1. The influence mechanism of protecting RIM on an asphalt concrete covering.
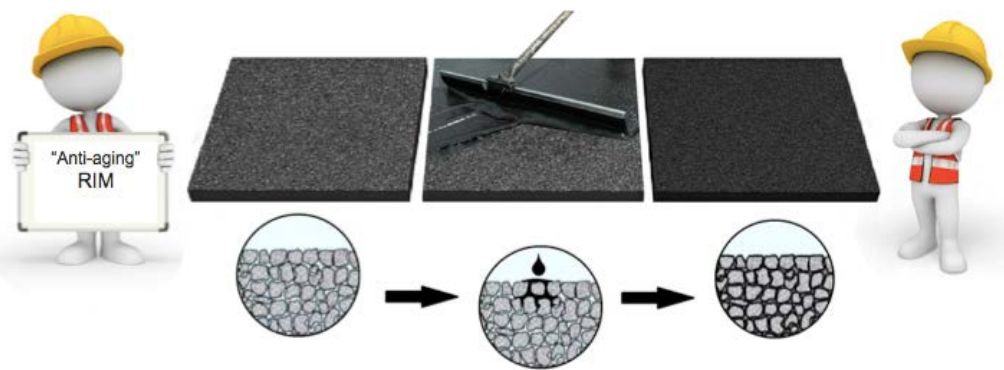

Protection from moisture,

oxidation, prevent peeling and

hairline cracks

Fig. 2. The influence mechanism of rejuvenating RIM on an asphalt concrete covering.

Therefore, we can explain the periodically received unsatisfactory result as there are no indicators allowing to estimate efficiency of impregnations in dynamics. Unfortunately, there are no specified requirements in a segment of road impregnating materials. And what is the cornerstone in choosing the RIM on the basis of which it is possible to recommend the use of the same impregnating material on the objects located in the Arctic and southern road zone? In search of answers to these questions, the group of authors has offered the assessment technique of the RIM efficiency modeling the influences experienced by an asphalt concrete covering during its operation in Central Federal District of the Russian Federation.

\section{Materials and Method}

For an error exception, preliminary sample preparation has been executed. The washer samples of asphalt concrete of type B prepared in vitro on a gyrator were exposed to a research. From received, in the course of compression, cylindrical samples middle parts were cut namely samples of a washer (figure 3) which then were dried up. 


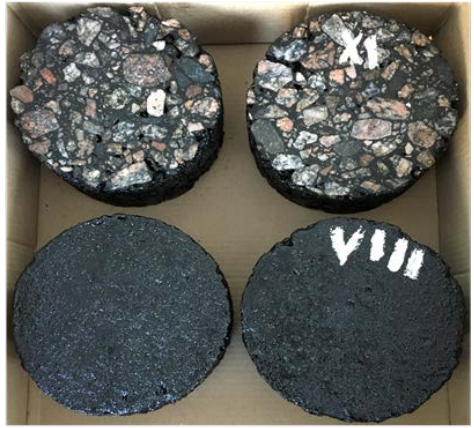

Fig. 3. A washer sample before and after processing with the RIM.

The prepared samples became covered with impregnating materials (Chem-Crete, Brit, Silkout, GEKOS (GKS)), according to the recommendations of the producer (on 9 samples). Drawing was carried out by a brush in several stages. Further samples were in identical conditions at a temperature of $20{ }^{\circ} \mathrm{C}$ within 3 days for formation of a protective film on their surface. Then, the effectiveness ratio of impregnating materials was determined by a technique [1].

$$
K_{\text {the efficiency of impregnation }}=\frac{W_{\text {without treatment }}}{W_{\text {with the proces } \sin g \text { RIM }}},
$$

where $W_{\text {without processing }}$ - water saturation of the control samples which aren't covered with the RIM, \%

$W_{\text {with processing with the PDM }}$ - water saturation of the samples covered with the RIM, \%

\section{Results and Discussion}

The obtained data are presented in figure 4.

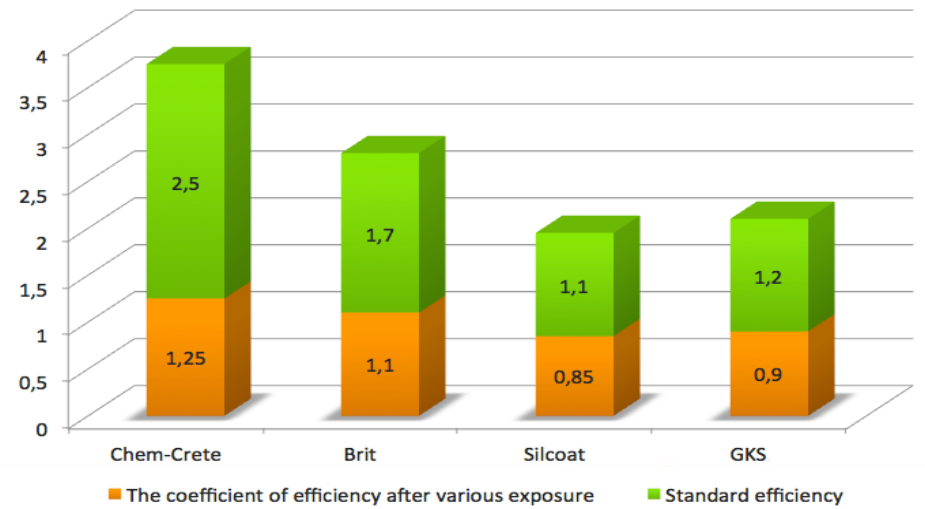

Fig. 4. Change of effectiveness ratio of the RIM under the influence of set of the natural factors simulated in laboratory.

For assessment of resistance of impregnating materials to various factors the following consecutive scheme of impact on samples has been offered.

The samples covered with the RIM:

- were explored on water penetration under pressure; 
- were saturated with water within the 24 hours period;

- were exposed to incubation at a temperature of $60{ }^{\circ} \mathrm{C}$ within 96 hours up to the constant weight;

- were frozen/thawed alternately for 10 cycles at a temperature of $-20{ }^{\circ} \mathrm{C}$;

- maintaining effectiveness ratio was estimated after a series of influences;

- were incubating during 1 hour at a temperature of $20^{\circ} \mathrm{C}$ and temperature of $0{ }^{\circ} \mathrm{C}(3$ samples on each test);

- were tested on durability at compression on forming, R'.

Each point of an experiment imitates certain operational conditions:

- Water penetration - impact of a wheel on a covering in the presence of moisture on it (effect of hydroplaning). It has been established that not all considered impregnations form a strong and waterproof layer on a covering, as a result of test such samples were saturated with water;

- Incubating - an experiment lasted for 4 days at a temperature of $60{ }^{\circ} \mathrm{C}$, however in the territory of Russia there are a lot of Federation subjects where summer temperatures warm a covering of the highway to higher rates;

- Freezing/thawing - the most adverse period for asphalt concrete is transition through $0^{\circ} \mathrm{C}$. As it has become clear, it is quite a destructive period for impregnating materials as well (fig. 5).

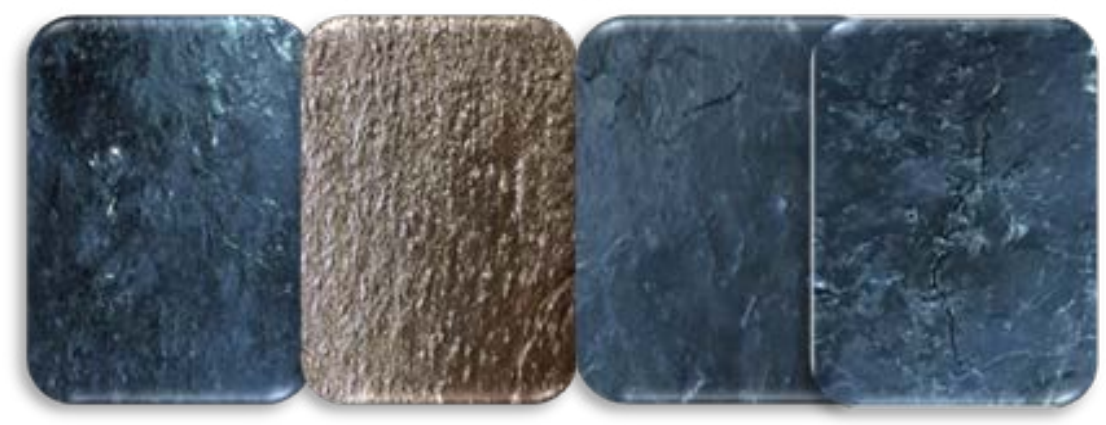

Fig. 5. A surface of the asphalt concrete samples covered with the RIM after the influence of the natural factors simulated in laboratory.

As it is clear from the figure on a surface of the samples covered with impregnations (two samples on the right), after a cycle of tests cracks have appeared. It is obvious that at more rigid and long cycles of freezing/thawing the intensity of crack formation on a surface of a covering will increase.

An interesting point is effectiveness ratio assessment after cycles of the described influences (figure 4). Apparently, it has considerably decreased. Moreover, according to the obtained data, water saturation of a number of the samples covered with impregnations has considerably increased rather than control series. And the efficiency of impregnations in the simulated conditions causes doubts.

The analysis of presented data (figure 6), illustrates the change of ultimate strength of the samples covered with the RIM on split at a temperature of $20^{\circ} \mathrm{C}$ after influence cycles. 


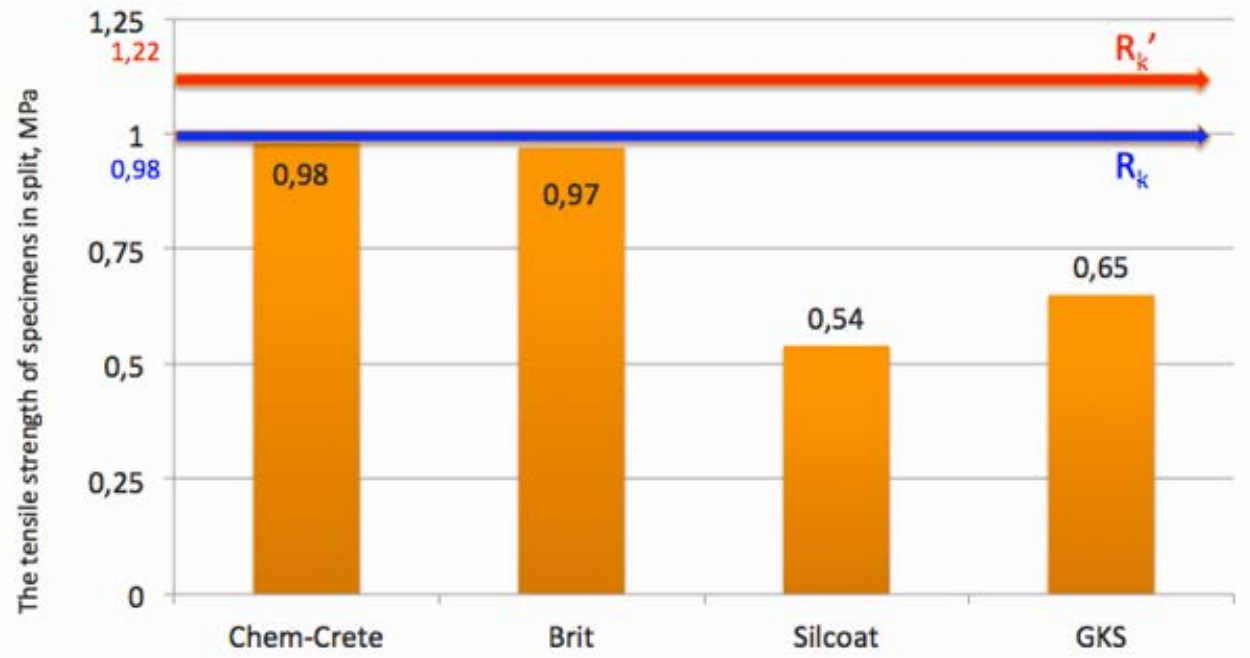

$R^{\prime}{ }_{k}$ and $R_{k}$ ultimate strength on split of the control samples which have undergone and not having been exposed to the simulated influences, respectively

Fig. 6. Influence of the RIM and the simulated factors on asphalt concrete durability at $20{ }^{\circ} \mathrm{C}$.

It is clear from the figure that the samples which weren't covered with the RIM and exposed to water and differences of temperatures $\left(\mathrm{R}_{\mathrm{k}}\right)$ are characterized by the largest durability in comparison with samples of a control series $\left(\mathrm{R}_{\mathrm{k}}\right)$ which was in water at a temperature of $20{ }^{\circ} \mathrm{C}$ within 1 hour, and concerning samples covered with the RIM. It is obvious that in the course of test, bitumen in their structure has aged, and this promoted the growth of strength indicators.

Analyzing the samples covered with the RIM they can conventionally be divided according to the influence on properties of asphalt concrete: keeping strength indicators at the level of control samples $\left(\mathrm{R}_{\mathrm{k}}\right)$ and reducing them considerably.

As a result of the conducted researches it is established that not all the RIM can effectively perform protective function when drawing on a covering of highways. The lack of knowledge of material behavior in specific operational conditions can cause troubles, connected not only with reduction of service life of an asphalt concrete covering, but also it premature withdrawal of an operational state.

\section{Conclusion}

On the basis of all above, it is possible to conclude:

- For assessment of efficiency of the RIM only static short-term tests for definition of water saturation of samples aren't sufficient.

- It is necessary to develop research techniques modeling complex influence of natural factors (long water saturation, freezing/thawing, high temperatures) typical for the region of the RIM use.

- Insufficiently investigated RIM are capable to reduce service life of an asphalt concrete covering, as well as to prematurely take it out of service.

The analysis of the conducted researches has shown that there is need of improvement of assessment technique of RIM efficiency and accumulation of information on their behavior in aggressive conditions imitating operational ones typical for of all road climatic zones. In selecting one or the other impregnating material it is necessary to have a rather 
exact forecast of its behavior in conditions of high or low temperature conditions, at long moistening, and the subsequent freezing. And only then, at implementation of the abovestated requirements, road impregnating materials will become "the reliable defender" of highway coverings.

\section{References}

1. ODM 218.3.073-2016 Recommendations on the use of impregnating structures for increase in durability of asphalt concrete coverings, M., FDA, p.53. (2016)

2. Government of the Russian Federation. About development of road infrastructure. The reference to a teleconference of measures for improvement of a condition of regional and municipal roads. Meeting 4/29/2016. Dmitry Medvedev, digital resource: www.government.ru. (2016)

3. M. Visotzkaya, Development of the effective nanomodified bituminous and polymeric mastic. Bulletin BSTU named after V.G. Shukhov, №6, pp. 87-92. (2015)

4. Patent 2195472 RF, MPKS 08 L 95/00. Impregnating structure on the basis of bituminous materials. Kucenko G., Kolosov G., Agapova T., applicant and patent holder of Federal State Unitary Enterprise Research Institute of Polymeric Materials, № 2001115462/04 application 05.06.2001, publ. 27.12.2002, Bul. № 36 .

5. Patent 2164505 RF, MPKS 04 B 41/84. Universal structure for impregnation of construction materials. Selskij B.,Perlov N., Bikbulatova V., applicant and patent holder Selskij B., Perlov N., № 99111845/03 application 01.06.1999, publ.27.03.2001, Bul. № 9.

6. Patent 2424262 RF, MPK S 08 L 95/00. Modified asphalt binding and compositions of an asphalt paving. Xyordzhenroter U., Byorner P., Rejdmecher K., applicant and patent holderFajerstounPolimers, LLK, Heritage Research Group, № 2008131056/04 application 22.12.2006; publ. 10.02.2010, Bul. № 4 .

7. Patent 2610510 RF, MPK S 08 L 95/00, E 01 S 7/35, S 08 K 3/34, S 08 K 5/5419. Way of receiving the impregnating composition on the basis of the modified bitumen applied to surface treatment of asphalt concrete coverings. Glushko A., Razinov A., Ryabenko V., applicant and patent holder FSI State awards of a labor red banner research institute of chemical reactants and especially pure chemicals, № 2015148791, application 13.11.2015; publ. 13.02.2017, Bul. № 5.

8. Patent 2290419 RF, MPK S 08 L 95/00. Material for restoration of asphalt concrete coverings. Kozlov G., Verenko V., Xlebcevich V., applicant and patent holder IRMAST-M closed joint stock company, Kozlov G., № 2005126908/04 application26.08.2005 publ. 27.12.2006, Bul. № 36 .

9. Patent 2516605 RF, MPK E 01 C 7/35, S 08 L 95/00. Way of processing of asphalt concrete pavings. Sandu R., Glushko A., Bulatitsky K., applicant and patent holder Ministry of Education and Science of the Russian Federation of Federal State Unitary Enterprise State awards of a labor red banner research institute of chemical reactants and especially pure chemicals, № 2012153391/03 appl. 11.12.2012, publ. 20.05.2014, Bul. № 14.

10. Patent 2612387 RF, MPK S 04 B 26/26, C 08 L 95/00, S 04 B 111/27. Materials for a bituminous paving and ways of their receiving. Rotc S., Xaker S., Ruan Yu.; applicant and patent holder HarnivalInternationalInc., № 2013135447 appl. 25.01.2012, publ. 10.03.2015, Bul. № 7 . 
11. Patent 2615377 RF, MPK S 08 L 95/00, S 04 B 26/26, E 01 S 7/35. Impregnating mix for protection asphalt concrete, concrete both pavings of various type and a way of her receiving. Novikov S., Yefimov M., Novikov R., applicant and patent holder Novikov S., Yefimov M., № 2015151349 appl.30.11.2015, publ. 04.04.2017, Bul. № 10 .

12. Patent 2407840 RF, MPK D 21 H 27/18, D 21 H 27/24, D 21 H 27/26, D 21 H 27/28. Sheeting from wear. Didavide M., Alari Jean-André, Kuntz P.,applicant and patent holder Centre For Abrasives And Refrectories Research And Development, № 2009142807/12,appl. 17.04.2008,publ. 27.12.2010, Bul. № 36.

13. Patent 2516397 RF, MPK S 09 D 5/08. Impregnating structure on a polymeasure to a basis of kolmatiruyushchy action an ultracord for protection of a blanket of concrete, the tsementnobetonnykh and asphalt concrete coverings. Priests V., Ogol V., Shkarupin A.,applicantPriests V., Ogol V., Shkarupin A., № 2012141650/05,appl. 01.10.2012, publ. 20.05.2014, Bul. № 14 .

14. A. Yuliestyan, M. García-Morales, E. Moreno, Assessment of modified lignin cationic emulsifier for bitumen emulsions used in road paving. Materials and Design, 131, pp. 242-251 (2017)

15. G. D'Angelo, D. LoPresti, N. Thom, Optimisation of bitumen emulsion properties for ballast stabilization. Materiales de Construccion, 67, Issue 327 (2017)

16. H. Asli, E. Ahmadinia, M. Zargar, M. R. Karim, Investigation on Physical Properties of Waste Cooking Oil-Rejuvenated Bitumen Binder. Construction and Building Materials, 37, pp. 398-405 (2012)

17. J. Lin, P. Gue, L. Wan, and S. Wu, Laboratory Investigation of Rejuvenator Seal Materials on Performances of Asphalt Mixtures. Construction and Building Materials, 37, pp. 41-45 (2012)

18. C. Chiu, M. Lee, Effectiveness of Seal Rejuvenators for Bituminous Pavement Surfaces. Journal of Testing and Evaluation, 34, Issue 5, pp. 390-394 (2006)

19. Y. Zhang, W. Verwaal, A. A. A. Molenaar, S.P. Wu, Using high-resolution industrial $C T$ scan to detect the distribution of rejuvenation products in porous asphalt concrete. Construction and Building Materials, 100, pp. 1-10 (2015) 